\title{
Biomimetic fibre-reinforced composites inspired by branched plant stems
}

\author{
T. Masselter ${ }^{1,2,3}$, T. Haushahn ${ }^{1}$, H. Schwager ${ }^{3,4}$, M. Milwich ${ }^{2,5}$, \\ R. Nathanson ${ }^{5}$, M. Gude ${ }^{6}$, F. Cichy ${ }^{6}$, W. Hufenbach ${ }^{6}$, \\ C. Neinhuis ${ }^{3,4} \&$ T. Speck ${ }^{1,2,3}$ \\ ${ }^{1}$ Plant Biomechanics Group Freiburg, Botanic Garden, \\ Faculty of Biology, University of Freiburg, Germany \\ ${ }^{2}$ Competence Network Biomimetics, Baden-Württemberg, Germany \\ ${ }^{3}$ Bionics Competence Network (BIOKON e.V.), Germany \\ ${ }^{4}$ Botanic Garden, TU Dresden, Germany \\ ${ }^{5}$ Institute for Textile Technology and Process Engineering Denkendorf, \\ Germany \\ ${ }^{6}$ Institute of Lightweight Engineering and Polymer Technology (ILK) TU \\ Dresden, Germany
}

\begin{abstract}
The manufacturing of nodal elements and/or ramifications with an optimised force flow is one of the major challenges in many areas of fibre-reinforced composite technology. Examples are hubs of wind-power plants, branching points of framework constructions in the building industry, aerospace, ramified vein prostheses in medical technology and the connecting nodes of axel carriers. Addressing this problem requires the adaptation of innovative manufacturing techniques and the implementation of novel mechanically optimised fibrereinforced structures. Consequently, the potential of hierarchically structured plant ramifications as concept generators for innovative, biomimetic branched fibre-reinforced composites was assessed by morphological and biomechanical analyses. Promising biological models were found in monocotyledons with anomalous secondary growth, i.e. Dracaena and Freycinetia, as well as in columnar cacti, such as Oreocereus and Corryocactus. These plants possess ramifications with a pronounced fibre matrix structure and a special hierarchical stem organization, which markedly differ from that of other woody plants by
\end{abstract}


consisting of isolated fibres and/or wood strands running in a partially lignified parenchymatous matrix. The angles of the $\mathrm{Y}$ - and $\mathrm{T}$-shaped ramifications in plants resemble those of the branched technical structures. Our preliminary investigations confirm that the ramifications possess mechanical properties that are promising for technical applications, such as a benign fracture behaviour, a good oscillation damping caused by high energy dissipation, and a high potential for lightweight construction. The results demonstrate the high potential for a successful technical transfer and will lead to the development of concepts for producing demonstrators in the lab-bench and pilot plant scales that already incorporate solutions inspired by nature.

Keywords: branched fibre-reinforced composites, $Y$ - and T-shaped ramifications, monocotyledons, columnar cacti, lightweight.

\section{Introduction}

The production of an ever increasing number and diversity of fibre-reinforced composites is driven by the high demand for lightweight materials with good damping, other beneficial mechanical properties and high standards for excellent performance in structures that are subjected to extreme tension, torsion and bending forces and moments. In many technical applications, these loadings are dynamic and thus especially critical for the structural integrity of the component, fig. 1 .

This is especially the case for mechanical parts that are subject to vibration and impact loads in fast moving objects like cars, planes or windmills. Failure of these structures often has catastrophic consequences and can lead to the collapse of the entire structure, e.g. the demolition of a windmill caused by the delamination of the rotor blades (www.bt.dk [1]). While fibre-reinforced composites hold the potential to meet these high performance standards, the production of such structures is often very difficult and complicated by the complex shape of many parts, especially branched elements. The combination of two approaches, i.e. the development of new production techniques combined
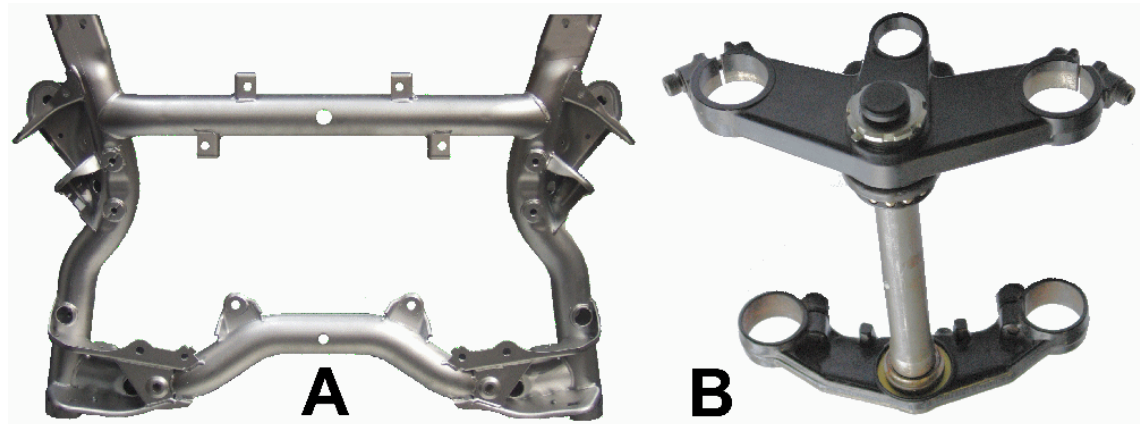

Figure 1: $\quad$ Metal cross-member from the company Ilsenburger Grobblech (A) and (B) metal fork bridge of a motorbike. 


\section{engineering}
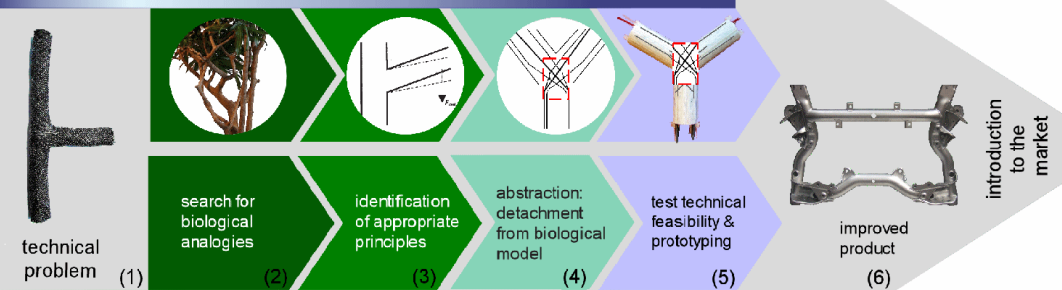

(6)

\section{biology}

Q 2009 Plant Biomechanics Group Freiburg (BIOKON \& Competence Network Biomimetics)

Figure 2: Top-Down Process (technology pull) for developing biomimetically optimised branched fibre-reinforced structures.

with a biomimetic optimisation of the inner and outer structure of the fibrereinforced composites, shall overcome these restrictions of classic engineering techniques for optimisation. The potential of nature as a role model for designing fibre-reinforced components is very high as 1) it combines different substructures into a superordinate structure thus optimising the mechanical characteristics, a principle that is common in nature, and 2) the laminated configuration of technical products, as e.g. a carbon-fibre-reinforced epoxy resin and some plant stems, as e.g. the layered structure of a bamboo shoot are highly comparable $[2,3]$. The general potential of biomimetic approaches will be described for the specific example of branched technical fibre-reinforced composites.

The methodological approach for developing 'branched' composite structures can be described as a 'Top-Down Process' as defined by the Plant Biomechanics Group Freiburg [2, 4], fig. 2.

\section{Methods}

An R\&D project in biomimetics may be initiated by a concrete technical problem posed by an engineer of a company (technology pull, 'Top-Down Process') ((1), fig. 2). The solution is often not limited to the constraint of one particular application, but rather can be implemented in a large number of products and may even generate new technical applications. The search for adequate concept generators in nature is the second step (2). This screening covers a broad spectrum of biological organisms in order to find the concept generators with the highest potential of 'solving' the technical problem. After completion of the screening procedure, appropriate principles based on structures and functions of one or more concept generators are identified (3). To analyse quantitatively the form-structure-function relationships of the model plants, an array of methods, including biomechanical tests as well different light- and electro-optical analyses (see below) are used. The abstraction process is the next 
step (4). This part of the project is highly important for the success of the whole project. The underlying principles that were found in the biological organisms are detached from these and translated to technical materials and structures. This knowledge-transfer from the biologists to the engineers forms the basis for assessing the possibilities for a technical implementation and makes it possible to carry out technical feasibility tests (5). In later steps, the natural structures are modelled and demonstrators are manufactured on the lab-bench scale and pilot plant scale prior to prototyping. The biomimetically optimised structures are then finally introduced onto the market, accompanied by flanking measures from the industrial partner (6).

Serial thin and semi-thin sections were made for analysing the anatomy of the branch-stem attachment regions of Dracaena and Freycinetia, two of the role models for branched biomimetic fibre-reinforced composites [5, 6].

First numerical structural analyses of stem-branches by Finite Element Analysis (FEA) for the investigation of geometric influences to the branch stiffness are performed at the Institute of Lightweight Engineering and Polymer Technology using 2D-models with shell elements which have been generated by a fringe pattern projection system, fig. 3 .

For analysing the external and internal organisation of the branching regions in monocotyledons and columnar cacti in detail, scanning electron microscopy and microtomography were employed, fig. 4. These methods allow transferring the morphology of the concept generators, e.g. Corryocactus brachypetalus (fig. 4A) into a three-dimensional model of the organisation of the wood lamella (fig. 4B) that can be used as a basis for generating a Finite-Element--model with approx. 30.000 volume elements for a structural analysis, fig.4C. Numerical simulations are used in order to investigate the influence of the inner structure of the plant stems on the deformation behaviour and to draw conclusions on the

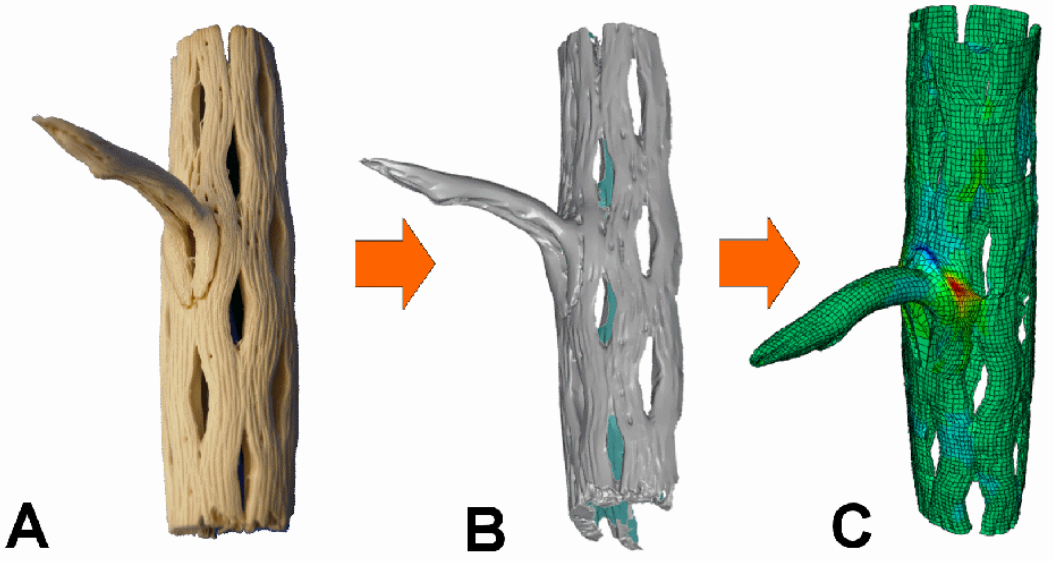

Figure 3: Oreocereus fossulatus: (A) anatomical analysis; (B) CADmodelling (fringe pattern projection system); (C) FE-simulation. 

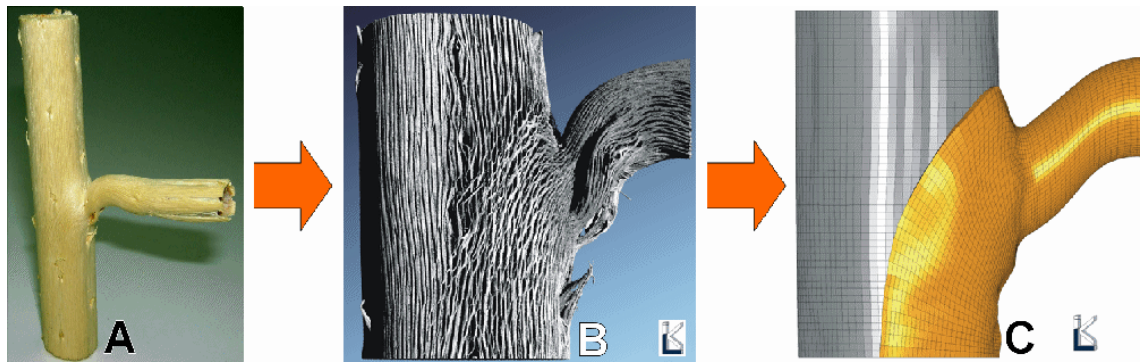

Figure 4: Stem-branch attachment regions of Corryocactus brachypetalus: (A) external view of the wood cylinder; (B) 3D-model of stem based on Micro-CT data; (C) mesh of FE model.

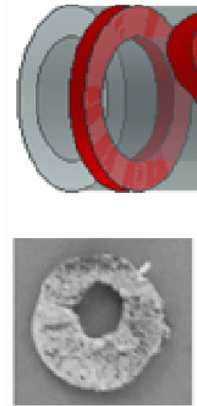

A

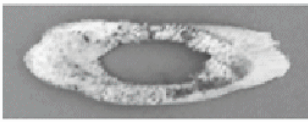

B

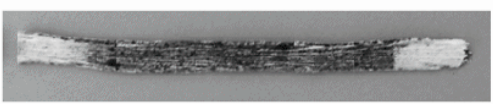

C

Figure 5: Material testing of lignified vascular tissue specimen of Corryocactus brachypetalus in different angles relative to the stem axis: (A) perpendicular to the stem axis; (B) in an angle of $30^{\circ}$; (C) parallel to the stem axis.

optimal fibre arrangement in technical composites structures. Required material properties such as the directional dependent Young's modulus, Poisson's ratio and shear modulus for the simulation are determined in extensive loading tests on natural specimens at the Botanical Garden, TU Dresden taking into the account the material's anisotropy, fig. 5.

For this purpose, the specimens out of the lignified vascular tissue were tested in monoaxial tensile tests with optical deformation analysis in different angles to the stem axis, fig. 5. Axially oriented strands were used to assess the Young's modulus in fibre direction and the axial-tangential and axial-radial Poisson's ratios, fig 5C. Due to the small diameter of the vascular cylinder of the investigated species Corryocactus brachypetalus, ring-shaped specimen had to be used for measuring the Young's modulus perpendicular to the fibre direction, fig. 5A. The Shear modulus was calculated in a polar transformation of the Young's modulus of ring-shaped specimen cut in an angle of $30^{\circ}$ to the stem axis, fig. 5B. For the missing material properties that are needed as input parameters for the Finite-Element-Analysis, appropriate assumptions were made. 

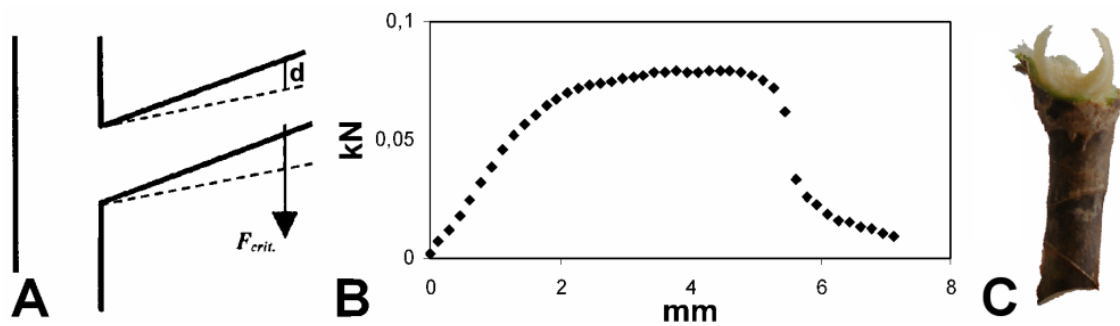

Figure 6: Breaking experiments: (A) schematic drawing of the geometry of the stem-branch attachment. The solid line represents a lateral twig before bending, the dashed line a lateral twig shortly before fracture, $F_{\text {crit }}$ is the critical force necessary to break the twig, $d$ is the vertical displacement until fracture; (B) exemplary forcedisplacement curve measured for Dracaena reflexa by the fracture mechanics test setup shown in (A); (C) sickle-shaped fracture mode.

Additionally, the biological concept generators were tested biomechanically at the botanic Garden of the University of Freiburg. These tests include breaking experiments in which a force is applied to a lateral twig until this twig breaks (fig. 6), using similar methods as described in detail in Beismann et al. [7]. This setup allows determining the force necessary to break the twig (fig. 6A) and the fracture toughness as well as the stress and strain (fig. 6B) at fracture and to characterise different fracture modes, fig. $6 \mathrm{C}$.

\section{Branched fibre-reinforced composites}

Monocotyledons like Dracaena and Freycinetia as well as columnar cacti like Oreocerus fossulatus (fig. 3) and Corryocactus brachypetalus (figs. 4, 5) show $\mathrm{Y}$ - and T-shaped branchings that in their angles resemble those of branched technical components. In these biological concept generators, isolated fibres and/or wood strands run in a partially lignified parenchymatous ground tissue matrix, so that they form per se natural fibre-reinforced composites, figs. 3, 4B, $7 \mathrm{C}, 8 \mathrm{C}$. The plants are hierarchically arranged on at least 5 levels: 1 ) the form of the branching (figs. 7B, 8B), 2) the arrangement of the fibre-bundles (fig. 7C) or wood strands (fig. 8C), the course of the individual fibre-bundles (fig. 7C) or the wood strands (fig. 8C), the anatomy of the fibre-bundles (fig. 7D) or wood strands (fig. 8D) and the ultra structure of the fibres or wood strands as well as 5) the gradients between fibre bundles/fibres/wood strands and matrix, figs. 7E, 8E.

While the axes of monocots and cacti are both optimised at these hierarchical levels, the morphology and hierarchical structuring of the stem-branch attachments differ in the two groups of plants: the angles, the course and the arrangement of the fibre bundles or wood strands in the matrix are highly different (compare figs. 7 and 8). 

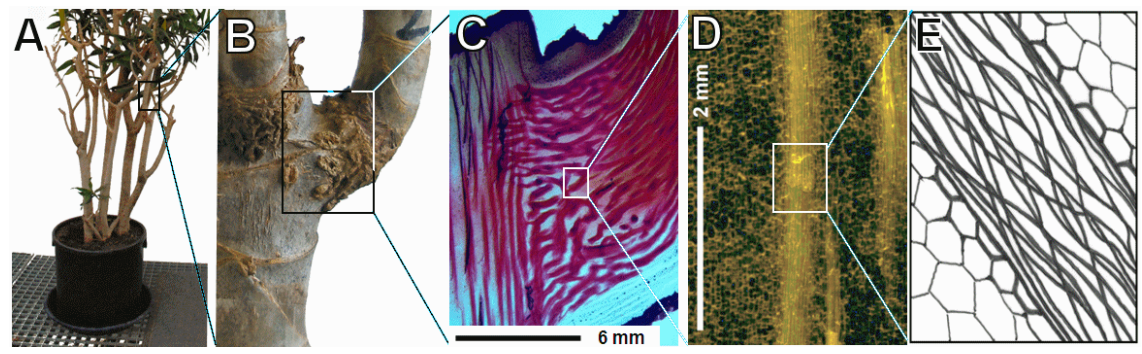

Figure 7: Hierarchical organisation of natural concept generators (Dracaena sp., monocotyledons): (A, B) form and diameter of stem-branch attachment region; (C) arrangement of the fibre bundles and course of the individual fibres; (D) anatomy of the fibre-bundles; (E) schematic ultra structure of the fibres as well as the gradients between fibre bundles/fibres and matrix.
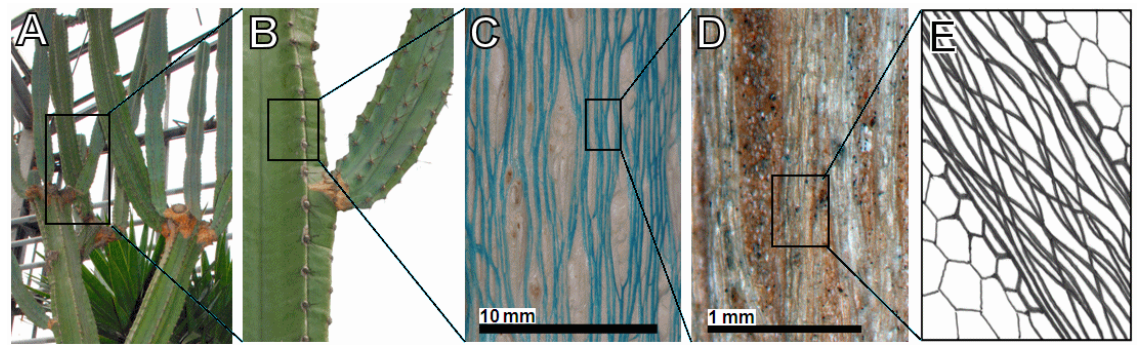

Figure 8: Hierarchical organisation of natural concept generators (Cereus sp., columnar cacti): (A, B) form and diameter of stem-branch attachment region; (C) arrangement of the fibre bundles and course of the individual wood strands; (D) anatomy of the wood strands; (E) schematic ultra structure of the strands as well as the gradients between strands and the matrix.

In Dracaena, a network of somewhat helically, but mostly paraxially arranged fibrous bundles in large parts of both stem and branch has developed in the course of evolution as an adaptation to complex loading conditions. Furthermore, this has led to a complex interwoven pattern in the regions where the branch is connected to the stem (fig. 7C). In simple terms, the stem and branch can be considered to be 1) non-hollow tubes that are interconnected by 2) a complex pattern of fibres with a 3) larger diameter at the interconnecting region.

In a similar way, the wood bands in stems and branches of columnar cacti are also more or less paraxially arranged showing net-like interconnection (fig. 8C) but in contrast, they form a very different pattern at the stem-branch interconnection, fig. 4B. The stems and branches of columnar cacti can be reduced to 1) woody tubes filled by a non-lignified parenchymatous pith with an 
interconnection displaying a 2) complex but differently arranged pattern of wood bands and 3 ) often a smaller diameter at the interconnection, figs. 4A, $8 \mathrm{~B}$.

Different modes of fracture with distinct force-displacement curves were found as first results for the fracture mechanics in the monocotyledons and cacti. One of these modes of fracture of D. reflexa is sickle-shaped, fig. 6C. This mode of fracture can be correlated with a force-displacement curve that shows a benign breaking behaviour, i.e. with a long plastic range as in fig. $6 \mathrm{~B}$.

The transfer of the branched biological role models into technical products requires the use of modern techniques and methods. The braiding technique is predestinated to transfer the optimised structures of the plants, above all the fibrous bundles, into technical products and manufacture tubular preforms. More specifically, the overbraiding technique or the 3D-rotary braiding technique is used to manufacture braids of elementary shapes, which can be used as reinforcement of lightweight structures [8-11]. In recent years, the producibility of braided branchings, which shall be used for the technical translation, has been proven in principle [8, 10]. A radial braiding unit (fig. 9A) was developed for producing first prototypes of braided-shaped preforms, fig. 9B.

The potential fields of implementation of the branched fibre-reinforced structures are similar to those of the 'technical plant stem', a fibrous composite structure developed by the Plant Biomechanics Group Freiburg and the Institute for Textile Technology and Process Engineering Denkendorf [12-14]. Additionally, the biomimetically optimised joints can connect tubular shaped fibre-reinforced composites and shall be able to bear high loads and moments following the example of the branched biological role models, figs. 3, 4, 5, 7, 8 . It is important to design these joints in a way that the continuation of the fibres from the tubular structures through the joint and to the next tubular structure is guaranteed, similar to the stem-branch attachment structures in columnar cacti (fig. 4B) and arborescent monocotyledons, fig. 7C. The mechanical load capacity in the joint can be adjusted to be higher than the load capacity in the tubes, if this is of technical interest. This can be done by adjusting the amount, the diameter and the arrangement pattern of the fibres in the joint and, following the example
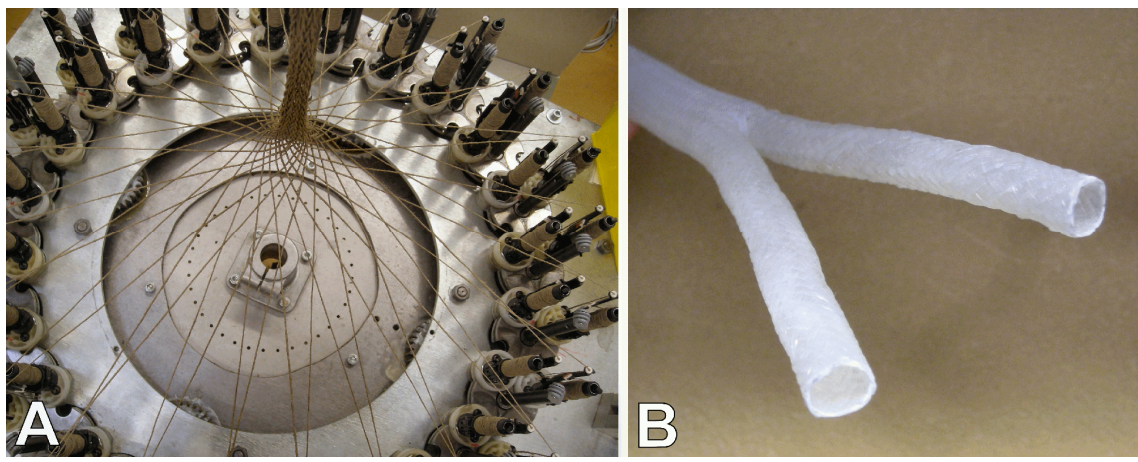

Figure 9: Radial braiding unit (A) and a first prototype of a braided T-shaped preform (B). 
of the biological concept generators, by implementing these adjustments on several hierarchical levels. Our goal is also to reduce cracks that form through excessive notch stresses in the joints and thus to increase the life-span and safety of components for automotive engineering (fig. 1), aerospace and many other areas of lightweight engineering.

\section{Acknowledgement}

We gratefully acknowledge the DFG for funding the study within the Priority Programme SPP 1420.

\section{References}

[1] bt.dk http://www.bt.dk/nyheder/vindmoelle-eksploderet, 20.01.2010, 9:43.

[2] Speck, T., Harder, D. \& Speck O., Gradient materials and self-repair: learning technology from biology. VDI-Report, B4284, pp. 1-13, 2007.

[3] Ehrenstein, G.W., Faserverbund-Kunststoffe: Werkstoffe, Verarbeitung, Eigenschaften. Hanser Fachbuchverlag: Muenchen, 2006.

[4] Speck, T. \& Speck, O., Process sequences in biomimetic research. Design and Nature IV, ed. C.A. Brebbia, WIT Press: Southampton, pp. 3-11, 2008.

[5] Masselter et al. (in prep.), Biomechanics and functional morphology in stem-branch connections of Dracaena reflexa and Freycinetia insignis.

[6] Masselter, T. \& Speck, T., From stems to sticks - what can we learn for biomimetics from natural fibre-reinforced structures? Proceedings of the $6^{\text {th }}$ Plant Biomechanics Conference, ed. B. Thibaut, ECOFOG: Cayenne, French-Guyana, pp. 357-366, 2009.

[7] Beismann, H., Wilhelmi, H., Baillères, H., Spatz, H.-C., Bogenrieder, A. \& Speck, T., Brittleness of twig bases in the genus Salix: fracture mechanics and ecological relevance. Journal of Experimental Botany, 51, pp. 617-633, 2000.

[8] Drechsler, K., Composites im Flugzeug- und Automobilbau. Conference proceedings of Denkendorfer Kolloquien, Technische Textilien, Denkendorf, 2001.

[9] Hufenbach, W., Blazejewski, W., Kroll, L., Böhm, R., Gude, M. \& Czulak, A., Manufacture and multi-axial test of composite tube specimen with braided glass fibre reinforcement. Journal of Material Processing Technology, 162/163, pp. 65-70, 2005.

[10] Cherif, C., Diestel, O. \& Gries, T., Textile Halbzeuge und Halbzeugfertigung. Textile Verbundbauweisen und Fertigungstechnologien für Leichtbaustrukturen des Fahrzeug- und Maschinenbaus, ed. W. Hufenbach, Progress-media Verlag: Dresden, 2007.

[11] Hufenbach, W., Textile Verbundbauweisen und Fertigungstechnologien für Leichtbaustrukturen des Maschinen- und Fahrzeugbaus. Sächsisches Druck- und Verlaghaus: Dresden, 2007 
[12] Speck, O., Milwich, M., Harder, D. \& Speck, T., Vom biologischen Vorbild zum technischen Produkt: der technische "Pflanzenhalm". Museo, 22, pp. 96-103, 2005.

[13] Milwich, M., Speck, T., Speck, O., Stegmaier, T. \& Planck, H., Biomimetics and technical textiles: solving engineering problems with the help of nature's wisdom. American Journal of Botany, 93, pp. 1455-1465, 2006.

[14] Milwich, M., Planck, H., Speck, T. \& Speck, O.: Der technische Pflanzenhalm: ein bionisches Schmaltextil. Melliand Textilberichte - Bandund Flechtindustrie, 44, pp. 34-38, 2007. 